\title{
ICONOGRAFIA ATOMÍSTICA E O PAPEL DA IMAGEM SEGUNDO GASTON BACHELARD
}

\author{
Lidia Queiroz* \\ liqueiroz@sapo.pt
}

RESUMO Este artigo pretende avaliar o papel da imagem na história do atomismo e sua relação com a ideia da visualização do invisivel da matéria, com enfoque nas perspectivas epistemológicas de Gaston Bachelard. As origens do atomismo estão ligadas à visão, mas é somente no final do século XVI que a iconografia atomistica surge. No artigo, a autora procura evidenciar a tentação humana para o "reino das imagens": (1) começando por explanar a importância da "metafísica da poeira" (segundo Bachelard, a poeira conferiu uma imagética fundadora à tese atomística); (2) fazendo notar que o termo "átomo" designou entidades diversas e ressaltando a importância conferida à geometria nas concepções atomísticas, tão presente ao longo da história do atomismo filosófico; (3) tecendo considerações sobre uma das primeiras imagens do átomo - Area Democriti, de Giordano Bruno; (4) colocando em destaque a problemática da imagem no atomismo contemporâneo e do seu radical abstracionismo; (5) explorando o paradoxo da utilidade das imagens a partir de várias obras bachelardianas; (6) mostrando que Bachelard não parece tomar a noção de imagem em sentido lato e que distinguir imagens de não-imagens é supor que ela tenha uma essência e classificação estável; e, por fim, (7) apontando para o fato de cada vez mais a filosofia da ciência tentar apurar qual a função que a iconografia pode ter na criação científica e na transmissão de conhecimento.

Palavras chave: Bachelard, Atomismo, Imagética, Iconografia Atomística 
Abstract: This article aims to evaluate the role of image in the history of atomism and its relation with the idea of visualization of the invisible of matter, focusing on the epistemological perspectives of Gaston Bachelard. The origins of atomism are linked to vision, but it is only in the late sixteenth century that the atomistic iconography appears. In the article, the author seeks to evince the human temptation to "the realm of images": (1) starting by expounding the importance of the "metaphysics of dust" (according to Bachelard, dust conferred a founder imagery to the atomistic thesis); (2) noting that the term "atom" has designated several entities and emphasizing the importance given to geometry in atomistic conceptions, so present throughout the history of philosophical atomism; (3) making considerations about one of the first images of the atom - Area Democriti, of Giordano Bruno; (4) by highlighting the problematics of the image in contemporary atomism and of its radical abstractionism; (5) exploring the paradox of the usefulness of images from various works of Bachelard; (6) showing that Bachelard does not seem to take the concept of image in a broad sense and that to distinguish images of non-images is to assume that it has an essence and stable classification; and, finally, (7) pointing to the fact that increasingly the philosophy of science attempts to investigate what function the iconography may have in scientific creation and transmission of knowledge.

Keywords: Bachelard, Atomism, Imagery, Atomistic Iconography

Embora a iconografia atomística apareça apenas no Renascimento ${ }^{1}$, "todo um mundo mesclado de imagens e razões estaria (...) já, em potência, nas primeiras doutrinas do atomismo" - conforme afirma Bachelard, em Les intuitions atomistiques (Essai de classification). A seu ver, a poeira é "a imagem mais simples do atomismo -, o que explica o fato de ser também uma imagem "duradoura" mo ingênuo. Será, então, em torno da "metafísica da poeira" que Bachelard começará o seu exame das intuições atomísticas, naquele ensaio.

Notemos o grão de poeira que paira num espaço fechado e escuro, no vazio, no qual entra um raio de sol... Ele era invisível: a sua existência só é revelada pela luz que penetrou aquele espaço. Só assim se tornou visível. Esta exda história do atomismo, da qual resulta este artigo, é financiada pela Fundação para a Ciência e a Tecnologia. 
periência singular "prepara e legitima uma passagem ao limite"4: "postulamos, então, o átomo da matéria no para-lá da experiência sensível", qualquer que ela seja. Os diversos fenômenos da poeira inspiraram a concepção atomística. O homem reconheceu na observação da poeira "uma prova" 6 empírica da doutrina atomística. Aquela imagem do movimento do grão de poeira no vazio é o que torna claro, por exemplo, o clinamen. A poeira confere uma imagética fundadora à tese atomística. Bachelard observa que "é perante os fenômenos da poeira, do pó e do fumo que [o homem] aprende a meditar na estrutura fina e no poder misterioso do infinitamente pequeno; seguindo essa via, ele está a caminho de um conhecimento do impalpável e do invisível"7.

Os atomistas antigos encaravam os átomos como os últimos constituintes da matéria: extensos, com diferentes formas e tamanhos. Eles seriam eternos, imutáveis, indivisíveis (embora fossem de uma certa grandeza), invisíveis (dada a sua pequenez) e com aptidão para a forma geométrica. Este último aspecto tem tanta relevância que encontraremos na Idade Média diversos autores a engenharem um tratamento geométrico das concepções atomísticas, em que os átomos são vistos como pontos geométricos. Isso pode ser explicado pelo fato de, durante a escolástica, o problema do contínuo ser analisado à luz da filosofia aristotélica e, no livro VI da Física, Aristóteles sustentara a tese da impossibilidade da composição dos contínuos por pontos. Assim, principalmente autores do período tardo-medieval, apresentam novos argumentos de caráter matemático que vêm corroborar a doutrina aristotélica. Com efeito, na história do atomismo filosófico, temos então dois tipos de indivisíveis ou átomos: os extensos e os inextensos ${ }^{8}$.

Ainda recorrendo à geometria, vemos atomistas e anti-atomistas medievais a elaborarem raciocínios nos quais está presente a concepção de que, para além dos pontos, as linhas e as superfícies possam ser também encaradas - assumindo-se uma perspectiva diferente - como indivisíveis (embora tenham partes). As três dimensões são fundamentais para se perceber como é que tal é concebível. Atente-se numa afirmação de Aristóteles, presente na Metafísica ${ }^{9}$, na qual se lê que uma linha é divisível numa dimensão, a superfície em duas, e um corpo o é em todas, isto é, das três maneiras. Por

4 Bachelard, [1933] 1975, p. 35.

5 Bachelard, [1933] 1975, p. 33.

6 Bachelard, [1933] 1975, p. 21.

7 Bachelard, [1933] 1975, p. 25. Com efeito, assim, "não há dúvida que existem, na literatura atomística, mais frequentemente de essência radicalmente materialista, numerosas citações relativas aos fenômenos da poeira" (Ibidem, p. 18-19).

8 Nos últimos anos, tem-se encetado novos estudos sobre o atomismo no período medieval e a historiografia é revista para dar conta de novas variações da tradição atomística, como se patenteia em Grellard \& Robert (Eds.) (2009).

9 Aristóteles, Metafísica, V, 6, 1016b26-28. 
conseguinte, o ponto é o absolutamente indivisível (pois não possui qualquer dimensão) e as linhas e as superfícies planas serão também indivisíveis: uma linha, indivisível nas duas dimensões que não possui (largura e profundidade), e uma superfície, na dimensão de que carece (a profundidade). É notório que, ao longo da história, o termo "átomo" tenha tido uma grande diversidade de aplicações. Ele pode designar entidades diversas.

Na Idade Média, o atomismo é discutido, majoritariamente, como um atomismo matemático. Os filósofos procuravam aplicar o cálculo matemático à resolução de problemas da filosofia natural. E aí "as palavras pontos, retas, [e superfícies] eram as imagens" - evocando uma ideia expressa por Gaston Bachelard em Essai sur la connaissance approchée $e^{10}$. Nos textos medievais em que discussões em torno do atomismo são consideradas, verifica-se então, muitas vezes, a necessidade de se desenhar as figuras que determinado enunciado reclamasse - o que ficava expresso no texto pelo verbo "facere", por indicações deste tipo: "Hec patet faciendo super rectam datam triangula quantorum laterum volueris" "1. Tratava-se de demonstrar uma hipótese ou tese fazendo figuras. Daí ser bastante pertinente a questão: “A prova é, então, verbal ou pictórica ou ambas?"12. É necessário um suporte visual para que os argumentos se tornem compreensíveis.

Como expusemos, as origens do atomismo estão então ligadas à visão, mas é somente no final do século XVI que se apresenta pela primeira vez uma representação gráfica do átomo, como veremos adiante.

Numa apreciação global de todas as formas de atomismo ideadas desde a Antiguidade até ao início do século XX, Bachelard considera que o atomismo "mais simples, o mais ingênuo"13, é o realista. Aliás, Bachelard está convencido de que o realismo é mesmo "um instinto", como afirma em La formation de l'esprit scientifique: contribution à une psychanalyse de la connaissance objective ${ }^{14}$, em que dedica um capítulo à "psicanálise do realista". O atomismo realista interno apresenta o átomo como uma substância rica em atributos. Para o atomismo realista, o que importa é discernir que qualidades pertencem à substância, distinguindo "o que é real e o que é ilusório no fenômeno" ${ }^{15}$. Nas palavras de Léopold Mabilleau, "consiste em associar as manifestações externas da matéria à sua

10 In De continuo, de Tomás Bradwardine - um tratado de natureza matemática, inspirado nos Elementos, de Euclides. Bradwardine, [século XIV] 2013.

11 Questão levantada em Lüthy \& Smets (2009, p. 436).

12 Bachelard, [1933] 1975, p. 13.

13 Bachelard, 1938, p. 131.

14 Bachelard, [1933] 1975, p. 46.

15 Mabilleau (1895, p. 534) citado por Bachelard, [(1933) 1975, p. 47]. 
constituição interna"16. Assim, há que encontrar o elo que liga a substância ao fenômeno, o interior (de uma entidade substancial) ao exterior ("uma série de qualidades aparentes e visíveis" ${ }^{17}$ ). O aprofundamento da posição realista leva-a por isso a tornar-se cada vez mais "coisista-. Declara aliás Bachelard que "o atomismo era a doutrina, por excelência, das coisinhas"18.

Com efeito, com o decorrer do tempo e a evolução dos sistemas, as qualidades fenomênicas passam a qualidades internas do próprio átomo. Por exemplo, como os seres físicos ou naturais manifestam coesão, há que explicar de que modo ela é conseguida por meio da união de átomos. Especula-se então que os átomos teriam ganchos, que lhes permitiriam encaixar-se uns nos outros, "fazendo passar também a coesão interatômica para o domínio intra-atômico, que se vê ao mesmo tempo dotado de uma coesão essencial- ${ }^{19}$. Na obra Le matérialisme rationnel, Bachelard fala mesmo desta tentação humana para o "reino das imagens" 20 , "tentação, continuamente ativa na história da filosofia, de explicar a matéria pela forma, de propor geometrias de átomos, acumulando e ajustando imagens poliédricas, imagens de ângulos e de ganchos..." ${ }_{21}$. Chega-se a reconhecer "o que há de ingênuo nessa imagem dos átomos enganchados" ${ }_{22}$, mas a mudança operada na concepção, recorrendo à noção de "afinidade", apresenta é, no fundo, um "realismo mais encoberto" 23 - declara Bachelard. A este respeito, vale a pena evocar uma reflexão de Werner Heisenberg sobre uma imagem do seu tempo de estudante que lhe ficou gravada na memória:

lembro-me ainda de uma figura que representava um grande número de átomos (...) o estado molecular de um gás. (...) ligavam-se uns aos outros por ganchos e colchetes (...) coisa tão tola. Pensava: se os átomos são (...) representáveis tão grosseiramente (...) é impossível que sejam os mais pequenos, indivisíveis elementos da matéria. ${ }^{24}$.

No livro La formation de l'esprit scientifique: contribution à une psychanalyse de la connaissance objective, Bachelard mostra que as tentativas de ligar qualidades externas ao interior da substância resultam em atribuições divergentes e ilustra este exercício com o caso da qualidade essencial de a água Heisenberg, s/d, p. 41. De fato, os "ganchos" dos átomos existem, embora não assumam a mesma forma que no macroscópico. 
tanto poder ser a suavidade (para uns) quanto a dureza (para outros). Com base nessas duas atribuições que contrastam entre si, mostra o "ridículo" - expressão do próprio Bachelard - do argumento. Assim, para Jules-Henri Pott,

não é a doçura, mas a dureza, que é a qualidade essencial da água. [E este é o argumento do químico alemão do século XVIII:] (...) “É preciso que as partículas da água sejam bastante duras, pois elas escavam as pedras e as rochas expostas ao seu movimento contínuo. Sabemos também que sentimos dor se batermos fortemente na superfície da água com a palma da mão". ${ }^{25}$.

Como acabamos de expor, as qualidades dos fenômenos passam então para a essência dos átomos. Não é pois de admirar que na filosofia atomística se passe a considerar a existência de átomos dos sabores, cheiros, sons, cores, etc. E as formas gométricas dos elementos que estão na base dos seres passam a constituir a explicação para o tipo de percepção que acabaremos por ter dos mesmos, pelo modo como afetarão os nossos sentidos (por exemplo, reconhecemos que um alimento é doce porque a sua matéria é constituída por átomos lisos, e que outro é picante porque na sua estrutura encontram-se átomos pontiagudos). As nossas sensações do mundo advêm de qualidades geométricas, primeiras; o resto são qualidades secundárias que reconhecemos ao real. Esse tipo de explicações torna-se cada vez mais sofisticado nos seus detalhes. E embora sejam ingênuas, "é a imagem em si que é interessante, porque nos fez compreender o tipo de raciocínio (...) que se podia então encontrar"26.

A iconografia atomística acabará por surgir no final do século XVI e pelas mãos de Giordano Bruno, que, com suas xilogravuras, grava as primeiras imagens do átomo em De triplici minimo et mensura. Estabelecendo uma aliança entre a filosofia e a pintura - afirmando que "os filósofos são, de certo modo, pintores (...); com efeito, não é um filósofo a não ser que imagine e pinte" 27 -, a obra deste autor coloca em destaque a relação ciência e arte (dado que, na pré-modernidade, ainda não havia a distinção entre ciência e filosofia). Desenhando a imagem do átomo, esta pode abrir a mente do leitor aos mistérios relativos à origem da matéria, contemplando algumas verdades sobre ela e conseguindo facilmente reter o que é essencial da doutrina atomística. O filósofo inclui essas ilustrações no texto mas não as explica; há então que descortinar as possíveis relações existentes entre aquelas e as teorias, perscrutando uma linha que nos leva das palavras/teorias às imagens.

26 "philosophi sunt quodammodo pictores (...); non est enim philosophus, nisi qui fingit et pingit". G. Bruno, [1583?] 1890, p. 133, linhas 20-24. 
São várias as figuras gravadas na obra bruniana supra citada, e Area Democriti é uma delas e sobre a qual teceremos algumas considerações.

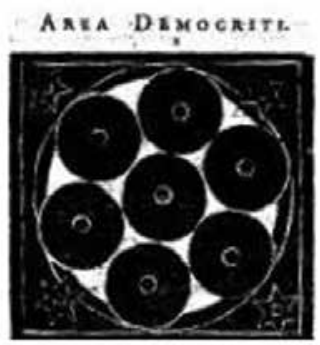

[Fig. 1: G. Bruno, 1591, p. 50. In: Lüthy (1998, p. 61)]

Tal como as outras, esta figura dá forma a um conjunto de doutrinas filosóficas. Nela vemos uma esfera rodeada por seis outras com o mesmo diâmetro e cada uma delas tem no seu centro um núcleo desenhado. Ela ilustra o crescimento cósmico: o mínimo (ou átomo) dá origem a tudo quanto existe pela sua auto-replicação sem fim - recordemos que Giordano Bruno é um defensor da concepção infinitista do universo -, sendo um princípio vital. Esse crescimento é estruturalmente geométrico (começando pelo ponto geométrico - note-se o mesmo na imagem) e a forma do mínimo de matéria não deixa de reaparecer na forma do máximo: do ponto ao átomo físico e deste aos Céus, como lembra também a imagem com a representação das estrelas de seis pontas e, de novo, com aquele núcleo ao centro. Para além disso, a aglomeração dos círculos dá forma a um hexágono e a um círculo maior. $\mathrm{E}$ a partir desse círculo maior, imaginemse depois outros seis círculos adicionados em seu redor, como primeiramente, e assim sem cessar. Para o filósofo, este seria o esquema invisível da expansão da matéria que continuamente emanaria dos átomos-mônadas. Daí ele escrever: "Atribuímos a mesma figura ao máximo e ao mínimo"28 - ou seja, ao macrocosmos e ao microcosmos - e "O mínimo é novamente visível em coisas grandes e na maior" ${ }^{29}$. Do átomo ao universo infinito, a área de matéria expande-se - tal como defendia Demócrito. No sistema de Giordano Bruno, "ponto, círculo e esfera são os três aspectos geométricos do princípio da unidade" ${ }_{30}$.

Mônada, ponto e átomo são três aspectos do conceito de mínimo (de triplici minimo). O diagrama Area Democriti é, para Giordano Bruno, um

28 "Rursum minimum in magnis et maximis esse perspicuum. " G. Bruno, [1591] 1889, p. 50, linha 6.

29 Lüthy (1998, p. 74).

30 “....archetypus (...) / Area Democriti proprio quae nomine dicta est”. G. Bruno, [1591] 1889, p. 51, linhas 5-8. 
"arquétipo"31. "ele descreve um padrão de crescimento universal que se aplica não só a todas as dimensões, como a entidades geométricas, físicas, cosmológicas e, na verdade também, numerológicas e espirituais-monádicas nos mesmos termos" 32 . Ele congrega várias teorias - expusemos já algumas -, como a da perfeição do número seis e a do círculo. Com efeito, aquelas seis esferas que circundam a esfera central não terá sido uma escolha inocente: para o pitagorismo, "6" é um "número perfeito". O conceito remonta aos pitagóricos e chama-se número perfeito àquele que é igual à soma dos seus divisores (excluindo ele mesmo, como divisor de si próprio). Os números perfeitos são muito raros e o primeiro deles é o 6 . Os divisores de 6 são 1,2 e 3 e $1+2+3=6$. Quanto à perfeição do círculo, "porque os seis pontos centrais dos círculos periféricos coincidem com as extremidades dos três diâmetros que passam pelo centro do círculo central, e porque os seis lados formados pela nova figura podem ser inscritos num novo círculo" 33 .

Em contraste com as doutrinas atomísticas gregas, o filósofo reconhece apenas uma forma para os elementos últimos da matéria: a esférica. Ora, o reconhecimento de uma única forma para o átomo dificulta a explicação da diversidade dos seres e fenômenos. Daí ter-se começado a idealizar mais formas atômicas a partir do século XVII (como é o caso de, entre muitos outros autores, Niklaas Hartsoecker), embora a imagética circular continue a manter-se como representação preferencial nos trabalhos de física e química (note-se, por exemplo, no simbolismo que John Dalton desenvolveu).

Desemboquemos na imagética atomística do século XX. Neste, a atomística funda-se num pensamento axiomático, que Bachelard apresenta, de um modo muito sugestivo, assim:

Vejam, através dos olhos da mente, esse mundo invisível. (...) Assegurem-se primeiro só de que tudo isso é possível racionalmente, isto é, que nenhuma contradição interna se introduziu nas vossas primeiras suposições. Tornai-vos também cientes de que nada de supérfluo foi suposto; dito de outro modo, que o sistema de postulados é completo e mesmo fechado. Uma vez tomadas todas estas precauções prévias, fechem os olhos ao real e confiai nas intuições intelectuais. Ireis construir um mundo racional e produzir fenômenos desconhecidos. ${ }^{34}$

Esta citação encontra-se em Les intuitions atomistiques e nela se patenteia uma mudança no modo de ver a própria visão. $\mathrm{O}$ ato de ver aparecerá depois e profundamente imbuído de compromissos teóricos. 
Assim, “é preciso compreender que [,por exemplo,] o microscópio é um prolongamento mais do espírito que do olho" 35 , conforme aponta em La formation de l'esprit scientifique: contribution à une psychanalyse de la connaissance objective. E isso porque todos os instrumentos de medida são, antes de mais, teorias reificadas. Aliás, "o olho atrás do microscópio aceitou totalmente a instrumentalização, ele mesmo tornou-se um aparelho atrás de um aparelho" 36 .

$\mathrm{O}$ atomismo contemporâneo tem como objeto de estudo um nãoobjeto: o infinitamente pequeno. O próprio modo de fazer ciência se altera. Como declara Bachelard, "enquanto a ciência usual se baseia nas coisas e procura os princípios, a ciência atômica estabelece os princípios e procura as coisas" ${ }^{37}$. Porém, as coisas visadas pela microfísica são nãocoisas: objetos designados pela terminação -on (próton, fóton, elétron...) que são nada mais do que objetos de pensamento e que se tornam objetos de experiências técnicas. A ciência atômica contemporânea cria mínimos materiais: na verdade, "aquilo que o homem $f a z$ numa técnica científica (...) não existe na natureza e não é sequer uma continuação natural dos fenômenos naturais" ${ }^{38}$. Produto de um racionalismo aplicado, o real é inventado (e não descoberto - como se, neste último caso, estivesse escondido) ${ }^{39}$ e realizado por meio de dispositivos fenomenotécnicos que acabam por alargar o domínio da fenomenologia. Em vez de uma ontologia temos uma ontogênese. A fenomenotécnica torna visível o invisível. ${ }^{40} \mathrm{O}$ átomo é um objeto altamente matematizado, descrito por funções matemáticas cada vez mais complexas. ${ }^{41}$ Ele é o exemplo por excelência de um objeto científico enquanto construto racional em estado puro.

36 Bachelard, [1933] 1975, p. 133.

37 Bachelard (1949, p. 103).

38 Bachelard, "Noumène et microphysique" (1970, p. 19): "uma fenomenotécnica pela qual fenômenos novos são não simplesmente encontrados mas inventados, construídos de raiz".

39 As primeiras imagens de átomos foram conseguidas pela técnica de microscopia iônica, pelo chamado microscópio iônico de campo. Foi em 1955 que o homem "viu" pela primeira vez átomos individuais. Aquele aparelho foi inventado precisamente para se tentar visualizar o átomo - o invisível da matéria -, o que o físico Erwin Müller e seus colaboradores conseguiram fazer experimentalmente. Mas já antes de 1955 havia imagens (e sons) em que se viam os rastros de partículas atômicas em câmaras de ionização ou câmaras de Wilson. A "visualização" dos fenômenos atômicos foi possível muito antes daquela data, embora de forma indireta. As experiências com a câmara de Wilson, repetidas em todos os laboratórios onde se investigava a radioatividade, transformaram completamente o modo como se considerava o átomo. Contemporaneamente existem mais aparelhos por meio dos quais se podem obter imagens de átomos, como o microscópio de efeito túnel (STM, "scanning tunneling microscope"). Imagens da visualização do invisível e de aparelhos em Galison (1997).

"Quando se acompanham os esforços do pensamento contemporâneo para compreender o átomo, é-se quase levado a pensar que o papel fundamental do átomo é o de obrigar os homens a fazer matemática." (Bachelard, 1940, p. 39). 
$\mathrm{Na}$ física contemporânea, o a priori ocupa um lugar de destaque. A percepção no sentido lato continua a ser tão importante quanto a reflexão, mas - há que notar - aquela é uma percepção construída e muito sofisticada. A visualização dos fenômenos não é direta. É assim que se pode então declarar, como faz Bachelard em L'activité rationaliste de la physique contemporaine, que "a ciência contemporânea libertou-se inteiramente da pré-história dos dados sensíveis" 42 ou, nas palavras de Max Planck, que "a atual cosmovisão científica oferece um aspecto estranho e realmente insólito. (...) Ver, ouvir e tocar não desempenham nela nenhum papel"43. A percepção deve dar indicações às teorias e permitir a utilização prática dos efeitos estudados; os dados da experimentação são fundamentais. No entanto, esses são dados que resultam de uma tecnologia construída para se verificar um real que foi pensado e que será realizado, isto é, um "real científico" 4 . É por isso que se pode então dizer que é verdade que se observam partículas subatômicas, mas que "o que se vê [por exemplo] na câmara de nuvens é um rasto, não se vê que é um rasto de electrões" $"$.

Que tipo de imagética está então associada à microfísica do século XX? Acompanhando a manifesta evolução no sentido do estudo do invisível, acabase por constatar o aumento da necessidade de se descreverem os fenômenos estudados por imagens "de ação" (e não "de objeto"), e de uma complexidade muitíssimo superior, ${ }^{45} \mathrm{o}$ que comporta maiores dificuldades de representação mental e iconográfica da matéria. O estudo da microfísica conduznos a uma desmaterialização da matéria. A matéria é energia, o átomo é coisa-movimento. A energia une a coisa e o movimento. Como se lê em Essai sur la connaissance approchée, " "Quod non agit non existit». (...) A existência é deduzida da ação. O que não pode ser detectado por nenhum aparelho, deve ser tido por não-existente, em física." ${ }^{46}$. O que é flagrante no infinitamente pequeno é a sua mobilidade extrema; o que se estuda são as propriedades e transformações energéticas da matéria. Podemos dizer que "pelo seu desenvolvimento energético, o átomo é devir assim como ser" ${ }^{\prime \prime}$. A matéria é descrita pela sua ação:

Por exemplo, o que é um fóton imóvel? Não se pode separar o fóton do seu raio, como gostaria, sem dúvida, de fazê-lo um coisista (...). (...) De uma maneira geral, parece que quanto mais pequeno é o objeto, melhor ele realiza o complexo de espaço-tempo, 
que é a própria essência do fenômeno. O materialismo alargado (...) leva assim naturalmente a associar a matéria e a radiação. (...) Antes de mais nada, é necessário considerar a matéria como um transformador de energia, como uma fonte de energia (...). (...) podemos ver como um movimento se torna uma coisa. ${ }^{48}$.

Por volta dos anos trinta, quando Bachelard escreve o ensaio Les intuitions atomistiques, a interpretação de Copenhagen da mecânica quântica estava muito em voga. Ora, segundo a interpretação ortodoxa da mecânica quântica (escola de Copenhagen), na física atômica e subatômica não é possível determinar simultaneamente a energia e a posição de uma partícula. Quer isto dizer que a matéria já não pode ser como que desenhada, com uma forma e localização precisas. O conceito científico de matéria liberta-se da descrição geométrica. O átomo muda de forma, ao receber ou perder energia, e assim temos um "infinitamente pequeno sem figura e sem repouso" ${ }^{4}$.

É então impossível representar espacialmente estruturas físicas sem ser por imagens "de ação" e mesmo assim, crê Bachelard, "nunca poderemos criar imagens aptas a representar a prolixidade de um devir e de um ser que romperam francamente com o nosso nível" ${ }_{50}$. Assim sendo, o epistemólogo posicionar-se-á criticamente quanto ao papel das imagens na construção e na comunicação do conhecimento científico. Em Le nouvel esprit scientifique, Bachelard declara que "a energia permanece sem figuras, não se lhe dá uma configuração a não ser indiretamente, ligando-a ao número" e que "virá um momento em que poderemos falar de uma configuração abstrata, de uma configuração sem figura" ${ }_{52}$.

Com efeito, quando Bachelard se debruça sobre as propriedades de partículas elementares, dizendo que estas podem ser expressas por imagens, ele afirma, por exemplo, que

não precisamos de completar, através de uma imagem, a relação entre o elétron e o comprimento de onda. Tomamo-los quase na desconexão de suposições elementares. Por que seríamos nós mais exigentes quanto ao caráter temporal (frequência ondulatória) do que em relação ao caráter espacial (forma do elétron)? É precisamente a teoria que constituirá o elo. Se se dá depois uma imagem, ela será apenas uma ilustração. Essa imagem será, por exemplo, uma curva ondulada fechada que lembrará as concavidades de uma corda vibrante. Mas não é esta imagem que nos fez pensar. Ela é tardia. As equações matemáticas são primordiais ${ }^{53}$. 
Correspondendo a uma espécie de prática, cada vez mais as equações estão onipresentes. $\mathrm{O}$ atomismo contemporâneo, designado como axiomático por Bachelard, "substituirá as primeiras imagens por axiomas (ou melhor, ele apenas aceitará essas imagens como formas de ilustrar os axiomas)"

No entanto, não concluamos precipitadamente que a apreciação bachelardiana do uso de imagens na ciência e no ensino da ciência se orienta num único sentido: no de uma crítica, que seria inflexível. Diferentemente, são várias as obras em que o autor expressa o paradoxo da utilidade das imagens. Por um lado, declara que elas cumprem um papel "pedagógico inelutável" 55 (em La philosophie du non) e, por outro, diz que "há que lutar contra o poder das imagens materiais" ${ }_{56}$ (em Le matérialisme rationnel), sustentando que "uma ciência que aceita as imagens é, mais que qualquer outra, vítima das metáforas" e, por isso, "o espírito científico deve lutar sempre contra as imagens" (em La formation de l'esprit scientifique). Na obra Le matérialisme rationnel, o filósofo afirma que "numa cultura científica, é preciso confinar as imagens (...) ao seu papel de luz efêmera" 58 . Repare-se que o autor atribui às imagens a capacidade de trazer "luz", embora - acrescenta prontamente - esta seja apenas "efêmera". Bachelard coloca ainda mais claramente esta questão no livro L'activité rationaliste de la physique contemporaine, dizendo que "as imagens (...) são, ao mesmo tempo, boas e más, indispensáveis e prejudiciais; é preciso usá-las com medida enquanto são boas e desembaraçar-se imediatamente delas quando se tornam inúteis" 59 . Portanto, com a sua crítica, o que Bachelard pretende assegurar é que as imagens não se tornem obstáculos epistemológicos ao espírito científico: elas terão de ser psicanalisadas, não poderão dar primado ao realismo, nem pretenderem passar por reflexos do real, nem tenderem a transformar o abstrato em coisas ou em esquemas gerais. Afinal, atinge-se a objetividade "quando tivermos certamente substituído o livro das imagens, folheado página por página, pela organização racional dos conceitos"60.

As imagens têm um poder de sedução sobre o homem, elas são constitutivas do seu ser, levando-o ao devaneio e satisfazendo-o na sua ânsia de

54 Bachelard, 1940, p. 139.

55 Bachelard, 1953, p. 29.

56 Bachelard, 1938, p. 38.

57 Bachelard, 1953, p. 29.

58 Bachelard, 1951, p. 94.

59 Bachelard, 1951, p. 74.

60 Schrödinger tinha outra posição relativamente a esta questão. Schrödinger (1996, p. 78-79): "Das vidas e das obras de Gassendi e Descartes, que introduziram o átomo na ciência moderna, sabemos como facto histórico que, ao fazê-lo, eles tinham plena consciência de que estavam a dar continuidade à teoria dos filósofos da Antiguidade cujos manuscritos tinham estudado diligentemente. Além disso, e ainda mais importante, todas as características básicas da teoria da Antiguidade sobreviveram na teoria moderna até à actualidade, bastante melhoradas e mais elaboradas, mas inalteradas, se aplicarmos o padrão do filósofo natural e não a perspectiva míope do especialista." 
conhecer. Essa satisfação pode levar a que o homem já não se ponha em busca da verdade, por julgar possuí-la já: mesmo que simples, uma imagem parece ser completude. Criam-se imagens para se tornar familiar um conhecimento abstrato. Crê-se que a exposição da teoria atômica com base em suportes visuais facilita a aprendizagem, dado que aquela assenta em conceitos abstratos e símbolos matemáticos incompreensíveis para os iniciados. Mas, no campo da ciência, a razão deve ironizar e não contemplar (pois que o espírito científico deve manter-se incessantemente vigilante quanto aos resultados alcançados e pronto para desconstruir conhecimentos que se descobrem com falhas). A posição bachelardiana quanto ao conhecimento do objeto da física e química contemporâneas parece indicar-nos uma dualidade composta pelos pólos "visualizar" ou "compreender", defendendo que a compreensão profunda exige que se abra mão da necessidade de visualização. Para o autor, a ciência é do domínio dos conceitos e a poética é que é do domínio das imagens.

A história da atomística testemunha um trânsito imagético que vai da percepção das imagens à geometrização (para representar o objeto átomo e depois fenômenos atômicos) e desta à pura abstração, como intentamos demonstrar. De fato, como escreve Michel Paty,

os desenvolvimentos da física que permitiram alcançar, do fim do século XIX ao início do século XX, a demonstração do caráter atômico da matéria, assim como da radiação, nos mostram bem como esses "átomos" modernos estão distantes das imagens que deles faziam os antigos. ${ }^{61} \mathrm{O}$ conceito de átomo físico tornou-se aí mais preciso e determinado, por meio de teorias matematizadas às quais a imagem parece absolutamente estranha (...). (...) permanece, sem dúvida, em alguma parte, nos processos de pensamento, um resíduo dessa imagem (...). A teoria, certamente, eliminou a imagem intuitiva e vaga, substituindo-a por uma rede de relações matemáticas ${ }^{62}$.

Estas declarações aproximam-nos já do que Bachelard admite em La philosophie du non, a saber, que "não nos parece (...) que se possa compreender o átomo da física moderna sem evocar a história da sua imagética, sem retomar as formas realistas e as formas racionais (...). (...) [pois] o átomo é exatamente a soma das críticas a que se submete a sua imagem primeira" ${ }^{3}$. O que se passa é que contemporaneamente o átomo não é então uma coisa (pelo contrário, ele é um bom exemplo da ilusão realista) e também não é uma imagem. O epistemólogo diz explicitamente, nessa obra, que "tal como aparece na microfísica contemporânea, o átomo é (...) [enquanto ultra-objeto], muito exatamente, a não-imagem" ${ }^{\circ 4}$. 
Compreende-se o sentido desta afirmação; no entanto, pode-se advogar que se os átomos são representados por equações, então são imagens (linguísticas). Bachelard não parece ali tomar a noção de imagem em sentido lato. De qualquer modo tem sido sobretudo contemporaneamente que se tem procurado desenvolver, com o maior rigor e amplitude possíveis, o que é uma imagem.

A palavra "imagem" possui uma extensão muito vasta, ela engloba inúmeras possibilidades. O que permite colocar diferentes categorias (como gráfico, mapa, símbolo, tabela, modelo, esquema, fórmula, pictograma, ilustração naturalista, fotografia, etc.) sob a designação comum de "imagem"? Indagar pela ontologia da imagem é supor que ela tenha uma essência. Torna-se extremamente difícil definir a natureza da "imagem" quando existem tantos tipos de imagens, desde as figurativas, as diagramáticas, as linguísticas e ainda as compostas. Continuam a ser "duvidosos" e "abertos à refutação" os seguintes pressupostos: "(1) existem critérios intemporais para distinguir imagens de não-imagens; (2) as imagens possuem um estatuto ontológico e epistêmico relativamente estáveis ao longo dos séculos; e (3) é possível desenvolver uma classificação estável ou taxonomia de imagens"

Não obstante todas as considerações apresentadas até aqui, a verdade é que nunca a ciência se construiu tanto com base em imagens como contemporaneamente. E finalmente esta linguagem visual começa a despertar um interesse cada vez mais significativo por parte dos filósofos da ciência, que passam a estudar as imagens científicas não como uma produção secundária no processo do conhecimento. Esta abordagem insere-se no recente movimento de reconhecimento de que a imagem em ciência ultrapassa o mero papel ilustrativo. Ela explora, portanto, o potencial da imagem não tanto pelo seu poder demonstrativo, mas sobretudo para apurar qual a função que a iconografia pode ter na criação científica e na transmissão de conhecimento.

\section{Referências}

ARISTÓTELES. "Metaphysics". Trad. W. D. Ross. In: BARNES, J. (Ed.) The complete works of Aristotle. The revised Oxford Translation, vol. II. Princeton: Princeton University Press, 1985 (p. 1552-1728).

BACHELARD, G. "Essai sur la connaissance approchée”. 5 ed. Paris: Vrin, [1928] 1981.

"Les intuitions atomistiques (Essai de classification)". 2 ed.

Paris: Vrin, [1933] 1975.

. "Noumène et microphysique". In: "Études". Paris: Vrin, 1970.

"Le nouvel esprit scientifique". 9 ed. Paris: PUF, [1934] 1966.

"Le matérialisme rationnel". Paris: PUF, 1953. 
. "L'activité rationaliste de la physique contemporaine". Paris: PUF, 1951. "Le rationalisme appliqué". Paris: PUF, 1949.

"La philosophie du non. Essai d'une philosophie du nouvel esprit scientifique". Paris: PUF, 1940.

. "La formation de l'esprit scientifique. Contribution à une psychanalyse de la connaissance objective". Paris: Vrin, 1938.

ELKINS, J.; NAEF, M. (Eds.) "What is an image?" Pennsylvania: The Pennsylvania State University Press, 2011.

GALISON, P. "Image and Logic: A Material Culture of Microphysics". Chicago-London: The University of Chicago Press, 1997.

GIORDANO BRUNO. "De triplici minimo et mensura". Francofurti, 1591, p. 50.

. "De minimo". Ed. F. Tocco \& H. Vitelli. "Iordani Bruni Nolani opera latine conscripta publicis sumptibus edita". Florentiae: Le Monnier, [1591] 1889. (Vol. I Pars III)

. "Explicatio triginta sigillorum". Ed. F. Tocco \& H. Vitelli, "Iordani Bruni Nolani opera latine conscripta publicis sumptibus edita". Florentiae: Le Monnier, [1583?] 1890. (Vol. II Pars II)

GRELLARD, C.; ROBERT, A. (Eds.) "Atomism in Late Medieval Philosophy and Theology". Leiden: Brill, 2009.

HEISENBERG, W. "A imagem da natureza na física moderna”. Trad. Mexia de Brito. Lisboa: Livros do Brasil, s/d.

LENOBLE, R. "História da ideia de natureza". Lisboa: Edições 70, 1990.

LÜTHY, C. "Centre, Circle, Circumference: Giordano Bruno's Astronomical Woodcuts". Journal for the History of Astronomy, 41, Cambridge, Science History Publications, 2010.

. "The Invention of Atomist Iconography". In: W. LEFÈVRE-J. RENNU. SCHOEPFLIN (Eds.). "The power of images in early modern science". Basel-Boston-Berlin: Birkhäuser Verlag, 2003.

. "Bruno's Area Democriti and the origins of atomist imagery". In: "Bruniana \& Campanelliana, Anno IV". Pisa-Roma: Istituti Editoriali e Poligrafici Internazionali, 1998/I.

LÜTHY, C.; SMETS, A. "Words, Lines, Diagrams, Images: Towards a History of Scientific Imagery". In: SYLLA, E. \& NEWMAN, W. (Eds.) "Evidence and interpretation in studies on early science and medicine. Essays in honor of John E. Murdoch". Leiden-Boston: Brill, 2009.

MABILLEAU, L. "Histoire de la philosophie atomistique". Paris: Imprimerie Nationale, 1895.

PATY, M. "A matéria roubada: a apropriação crítica do objeto da física contemporânea”. Trad. Mary Amazonas Leite de Barros. São Paulo: Edusp, 1995.

PLANCK, M. "Autobiografía científica y últimos escritos". Madrid: Nivola Libros Ediciones, 2000.

RIBEIRO, C. "Electrões inobserváveis e estrelas invisíveis. Em torno do problema do realismo em ciência: Bas C. van Fraassen versus Alan Musgrave". Lisboa: Centro de 
Filosofia das Ciências da Universidade de Lisboa, 2009.

SCHRÖDINGER, E. “A natureza e os gregos seguido de ciência e humanismo”. Lisboa: Edições 70, 1996.

TOMÁS BRADWARDINE. "De continuo", introd., trad. e notas por Lídia Queiroz, texto latino por J. Murdoch (†), prefácio J. Meirinhos. Porto: Afrontamento, 2013. 